\title{
О роли польскоязычных сочинений иезуитов в православной литературе Речи Посполитой XVI-XVII вв.
}

\author{
МАРГАРИТА А. КОРЗО \\ Margarita A. KoRzo, Институт философии РAH, ул. Гончарная, д. 12/1, RU-109240 Москва \\ Institute of Philosophy, Russian Academy of Sciences \\ E-mail: ma.korzo@gmail.com
}

(Received: 9 February 2018; accepted: 27 June 2018)

\begin{abstract}
The history of the works composed by Jesuits Fulvio Androzzi (1523-1575) and Marcin Śmiglecki (1563/1564-1618) and their translations into Church Slavonic as well as the so-called "prostaâ mova" are considered as an interesting example of the spread of Catholic works among adherents of Orthodoxy in the Polish-Lithuanian Commonwealth. Androzzi's Della frequenza della communione (1579) was originally an essay on the preparation for frequent communion. Its two Polish-language editions by Stanisław Grochowski (Scieszka poboznego chrześcianina, 1600) and Szymon Wysocki (Skarbnica duchowna, 1600) served as a source for a concise funerary sample-sermon written in "prostaâ mova" which is found in the Vilna's Orthodox Ritual (1621). An essay on theological and legal aspects of money-lending (usury) by Marcin Śmiglecki (O lichwie i trzech przedniejszych kontraktach, 1596) was partly used for drawing up a treatise on moral theology Mir s Bogom čeloveku (1669) published in the Kiev Monastery of the Caves. Both sample-sermons and treatises on moral theology were new literary genres for Orthodox tradition; their origin in the 17th century can be associated with Catholic influences. In both cases, the question of a translator from Polish into Church Slavonic and "prostaâ mova" remains open.
\end{abstract}

Keywords: Fulvio Androzzi, Marcin Śmiglecki, Orthodox religious literature, Orthodox rituals, sample-sermons, Orthodox manuals on moral theology, literary contacts

Одной из характерных особенностей православной литературы Речи Посполитой конца XVI - начала XVII вв. было появление новых разновидностей религиозных текстов, слабо представленных в предшествующие эпохи или совершенно неизвестных православной традиции. Подобное расширение жанрового поля можно считать следствием более интенсивных литературных контактов и более активного интереса православных книжников как к польским, так и к латинским текстам. Новые формы литературного взаимодействия были вызваны к жизни не в последнюю очередь ситуацией напряженного религиозного противостояния в Речи Посполитой на рубеже XVI-XVII вв., когда приверженцы православия были вынуждены утверждать и отстаивать свою конфессиональную идентичность в постоянной полемике с католиками и с униатами. При этом данный литературный интерес никак нельзя назвать взаимным: не удалось выявить ни одного случая, когда оригинальное бого- 
словское сочинение православного автора было, например, переведено на польский язык и получило распространение в католической среде.

Но не только ситуация полемического противостояния порождала обращение православных авторов к религиозным текстам их конфессиональных оппонентов. Данный интерес стимулировался и осознанием необходимости серьезных реформ в области духовного образования и религиозного наставления верующих; именно католический посттридентский опыт зачастую служил для этих реформ образцом для подражания.

О том, какие конкретно польские и латинские книги попадали в поле зрения православных авторов, можно судить в первую очередь по составу библиотек и книжных собраний православных братств, монастырей, реже частных лиц (CHARIPOVA 2006, IсАєвИч 2002: 355-378, ШустовА 2009: 533540). При этом исследователи отмечают, что сохранившиеся описания разного рода книжных собраний лишь в очень ограниченной степени отражают меру реального знакомства православных авторов с иностранной книгой. Поскольку существовала практика, что некоторые выходцы из Киевской митрополии получали образование в коллегиях иезуитов, то вполне вероятно, что эти православные студенты во время процесса обучения использовали и книжный ресурс католических учебных заведений. Учитывая наличие личных контактов между представителями православного и католического духовенства (Яковенко 2017: 105-106, ЯРЕМЕНКо 2007: 51-53), можно осторожно предположить, что в ряде случаев для православных книжников могли быть доступны и библиотечные собрания отдельных монашеских орденов. ${ }^{1}$

Одним из методов, который мог бы помочь хотя бы отчасти расширить наши знания о степени знакомства православных книжников с иностранной книгой, является реконструкция т. н. «библиотечного ресурса», который был задействован при создании того или иного сочинения. Данный подход был продуктивно использован в монографии, посвященной литературному и богословскому наследию одного из наиболее плодовитых украинских писателей XVII в. Иоанникия Галятовского (Яковенко 2017: 97-116). Главная сложность, которая подстерегает исследователя на этом пути, заключается в том, что далеко не каждый автор той эпохи напрямую проговаривает источники своей эрудиции в виде отсылок в тексте или выносных ссылок на полях. И даже этим ссылкам не всегда можно доверять в полной мере, поскольку в книжной традиции той эпохи еще не было принципиальной разницы между прямым цитированием источника и цитированием каких-то текстов с «чужих слов» или в чьем-то пересказе (BROGI BERCOFF 1992-1993: 329).

Одним из более трудоемких путей по реконструкции «библиотечного ресурса» того или иного сочинения является выявление иноконфессиональных текстов, фрагменты из которых присутствуют в анализируемом памятнике в «спрятанном» виде. В настоящем исследовании будут рассмотрены

\footnotetext{
${ }^{1}$ Известен, например, казус, когда благодаря личному знакомству лютеранин получил доступ к библиотеке доминиканского конвента в Вильне (NIEDŹWIEDŹ 2012: 98). 
два примера православных сочинений, составители которых использовали труды католических авторов (в данном случае - иезуитов), но не оставили читателям никаких подсказок о конкретных источниках своей эрудиции. Выбранные нами примеры принадлежат к тем жанрам религиозной литературы, которые появляются в православной письменности лишь в XVII в. под влиянием католической традиции - это т. н. проповеди-образцы и трактат по моральному богословию.

Проповеди-образцы или подборки сюжетов и библейских фрагментов на конкретную тему, которые потенциально могли служить развернутым планом для составления духовным лицом авторского поучения, были впервые опубликованы в приложении к церковнославянскому Требнику виленского братства 1621 г. Подборка включала тексты на «простой мове» на таинство исповеди, заключение брака и на погребение. Поскольку все три текста стилистически очень отличаются друг от друга и каждый из них заслуживает самостоятельного анализа, мы остановимся в настоящем исследовании в качестве примера только на образце погребального наставления.

«Казане на Погребе» (Требник 1621: 15 нн.об.-19 нн.об.) представляет собой рассуждение на слова пророка Иеремии «Не плачьте об умершем и не жалейте о нем» (Иерем 22:10). Текст разделен на десять лаконичных пунктов, в которых приводятся аргументы против чрезмерных форм горевания и плача об умерших; каждый из них подкрепляется подборкой цитат из Священного Писания. Текст обрывается словами «и прочая, и прочая», оставляя для потенциального проповедника возможность по своему усмотрению расширить перечень предложенных аргументов.

Как известно, традиция погребальных речей различных жанров восходит еще к античности и правила составления подобного рода «ораций» встречаются во многих пособиях по красноречию древности. Однако при этом исследователи едины во мнении, что жанр организованных по пунктам проповедей-образцов ${ }^{2}$ (иначе называемых «материями» от лат. «materia») получил развитие только в западнохристианском ареале (SCHRÖDER 2001). Подобного рода «материи» встречались в сочинениях очень разных жанров: в специализированных пособиях по гомилетике; в различных энциклопедических изданиях, организованных по алфавитному принципу; в церковных пособиях по риторике. C XVI в. первоначально в протестантских, а затем и в католических регионах все большее распространение получают специализированные компендиумы погребальных речей (т. н. «oratio funebris» или «Leichenpredigt» в немецкоязычных регионах) (Boge-BogNer 1999, WINKLER 1967). Потенциальным источником «материй» для погребальной проповеди могли служить также т. н. «книги утешений» (лат. liber consolationis, нем. Trostbuch), которые в раннее Новое время получили наиболее широкое распространение среди последователей лютеранизма (ScHOTтROFF 2012).

${ }^{2}$ В подобной организации религиозного поучения по пунктам исследователи усматривают влияние схоластического типа аргументации (SKWARA 1999: 325). 
Православной книжности на землях Речи Посполитой также был известен жанр погребального поучения. ${ }^{3}$ Можно сослаться на столь популярные на рубеже XVI-XVII вв. рукописные Учительные Евангелия (ЧуьА 2011) и на поучения в составе первоначально рукописных, а потом и печатных Прологов (ЧистяковА 2017). Но сам жанр авторских погребальных слов зарождается позднее. Самыми ранними примерами можно считать «Поученїе при погребе Софіей княгынї Чарторыской» (1618) видного деятеля братского движения Лаврентия Зизания и «Поученїе на преставленіе верьного человека, надгробное sело душе полезное» в составе Евангелия учительного (Рохманов, 1619) принявшего позднее унию Кирилла Транквиллиона Ставровецкого. Авторские поучения на погребение создавались православными авторами и в последствии, хотя по численности серьезно уступали текстам этого жанра как католиков, так и протестантов (SKWARA 2009). При этом проповеди-образцы были в православной письменности большой редкостью: лишь в середине XVII в. Иоанникий Галятовский помещает в гомилетическом сборнике собственного авторства Ключъ разуменія (Киев, 1659) четыре образца погребальных проповедей для представителей различных групп и сословий.

Поскольку составители проповеди-образца на погребение в составе Требника 1621 г. не имели в распоряжении текстов этого жанра из своей конфессиональной традиции, они могли потенциально использовать в качестве источника один (или одновременно несколько) из перечисленных западноевропейских жанров, в которых встречались соответствующего содержания «материи». При этом аргументы в пользу выбора конкретного сочинения могли быть, как представляется, самыми разными и не обязательно решающим был аргумент наличия данного сочинения в библиотеке виленского братства или в библиотеке одного из входящих в братство монастырей.

В данном конкретном случае в основу православной проповеди-образца был положен небольшой фрагмент из сочинения Della frequenza della communione итальянского иезуита, ректора коллегий Общества во Флоренции и Ферраре, духовного писателя Фульвио Андроцци (Fulvio Androzzi, 15231575). Сочинение было опубликовано первоначально на итальянском языке в составе трехтомного собрания сочинений иезуита в 1579 г., затем неоднократно переиздавалось самостоятельно. Латинский перевод Considerationes de frequentanda communio вышел из печати в 1598 году, за ним последовали многочисленные переводы на национальные языки. О востребованности сочинения Андроцци может свидетельствовать и тот факт, что известны, по крайней мере, три немецких перевода его текста о практике частого причастия, сделанные независимо друг от друга на рубеже XVI-XVII вв. разными авторами (BACKeR-SOMMERVOGEL 1890: 381-384, HeAley 2011: 364). На популярность Андроцци могло повлиять и обстоятельство, что его труды были перечислены в известном библиографическом своде Apparatus Sacer иезуита

${ }^{3}$ В данном случае мы не имеем в виду погребальные «речи» и «жалобные вирши» светского характера, хотя и в них зачастую встречались христианские мотивы. 
Антонио Поссевино (Possevino 1606: 38), на который зачастую ориентировались библиотекари католических учебных заведений, подбирая книжный фонд для той или иной коллегии.

В Речи Посполитой сочинения Андроцци также не остались без внимания (KAPUŚCIŃSKA 2016). Интересующий нас трактат о практике частого причастия был переведен одновременно двумя разными духовными лицами. В первом случае речь идет о краковском канонике, выпускнике коллегии иезуитов в Пултуске Станиславе Гроховском (Stanisław Grochowski, 15421612). Из сочинения Андроцци он сделал тематическую подборку сюжетов об очищении совести как подготовке к принятию причастия и опубликовал ее в виде небольшой брошюры Scieszka poboznego chrześcianina в 1600 году в Кракове. Через год брошюра была переиздана без изменений, но с другим вариантом предисловия. Лишь в версии 1608 г. на титульном листе появилось упоминание о том, что сочинение является компиляцией из трудов некоего итальянского иезуита («Z Włoskich scriptow Kapłana iednego SI»). Но ни тогда, ни ранее имя Андроцци названо не было. Перевод Гроховского был вновь переиздан в Познани в 1647 и 1648 гг. с некоторыми исправлениями (как указано в названии), но чем были продиктованы данные исправления и делались ли они с привлечением итальянского или латинского оригинала сказать невозможно, поскольку познаньский издатель не называет Андроцци в качестве автора сочинения.

Другая, совершенно независимая от Гроховского попытка перевода была предпринята польским иезуитом Шимоном Высоцким (Szymon Wysocki, 1546-1622). Он переложил все три тома трудов Андроцци, но издал их как самостоятельные сочинения между 1600 и 1611 гг. Интересующий нас трактат о практике частого причастия был переведен на этот раз в полном объеме и вышел из печати в 1600 г. в Вильне под названием Skarbnica duchowna.

Вполне закономерно предположить, что составители проповеди-образца из Требника 1621 г. обратили внимание на сочинение Андроцци именно благодаря наличию его польских переводов. Но чей именно перевод был использован виленскими братчиками - сказать невозможно: им были доступны не только книжные новинки католических типографий в Вильне, но и книжная продукция краковских издательских домов (ТOPOLSKA 1984: 169-170). Как было отмечено выше, сочинение о практике частого причастия было использовано православными не в полном объеме, был взят лишь небольшой его фрагмент: в итальянской версии он называется «Rimedij per consolar i tribolati per la morte di alcuno», в латинской - «Remedia ad consolandum afflictos ex morte cognati vel amici tristes», Станислав Гроховский перевел его как «Lekarstwa na kłopot, po śmierci y odeszciu miłego przyiaciela» (Scieszka 1600: $28 \mathrm{v} .-29 \mathrm{v}$.). В данном фрагменте перечисляются аргументы, могущие утешить христианина, горюющего после потери близкого родственника или друга. В сочинении Андроцци эти «remedia» анализируются в контексте рассуждений о неспокойной (неуверенной) совести наряду с другими «лекарствами» на всевозможные возникающие в жизни христианина ситуации принятия 
нравственных решений. Но вырванные из контекста сочинения Андроцци, «remedia» меняют свою функцию и вполне могут быть причислены к жанру утешения или consolatio. Именно в таком качестве данный фрагмент и был использован виленскими братчиками в Требнике 1621 г. Перелагая польский текст на «простую мову», они совершили лишь минимальное его редактирование, изъяв все ссылки на латинских богословов (например, Петра Ломбардского, Бернарда Клервосского) и расширив текст за счет новых цитат из Священного Писания.

Вторым примером православного сочинения, составители которого использовали труды иезуитов, является весьма объемный церковнославянский трактат по моральному богословию Мир с Богом человеку, опубликованный в типографии Киево-Печерской Лавры в 1669 г. Есть все основания предполагать, что над составлением трактата работало несколько человек, а архимандрит Лавры Иннокентий Гизель всего лишь благословил данный труд.

Католическое моральное богословие как самостоятельная область знания выделяется из богословия догматического лишь во второй половине XVI в. сначала у доминиканцев, а позднее - у иезуитов. Моральное богословие существовало долгое время исключительно как прикладная школьная дисциплина, необходимая для подготовки квалифицированных исповедников, а потому ее содержание исчерпывалось практическими вопросами: как адекватно квалифицировать греховные поступки и налагать соответствующее их тяжести церковное наказание, а также решать возникающие во время исповеди нравственные коллизии. В православных учебных заведениях XVII в. моральное богословие как самостоятельная дисциплина не преподавалось; сугубо же богословские предметы читались в Киево-Могилянской коллегии (а затем и Академии) на латинском языке. Поэтому вполне закономерно предположить, что церковнославянский Мир с Богом изначально задумывался не как учебное пособие, но как сочинение для традиционного в восточнославянских регионах келейного чтения духовенства. В свое время нами был уже отмечен компилятивный характер этого памятника (KoRzo 2012), который представляет собой своего рода мозаику, собранную из фрагментов сочинений очень разных жанров, не все из которых удалось пока идентифицировать.

В настоящем исследовании мы остановимся лишь на одном фрагменте Мира с Богом, а именно на рассуждениях о ростовщичестве («О разсужденіи лихвы»), помещенных в последней третьей части трактата, в контексте рассмотрения обязанностей и поведения духовника перед началом, во время и после исповеди (МБ 1669: 535-547). В данном параграфе анализируются разнообразные ситуации дачи денег в долг и приводятся опровержения «изветов» ростовщиков, которые пытаются оправдать свои греховные действия благими намерениями. Поскольку перед нами первый случай интереса православных авторов Речи Посполитой к данной тематике в XVII веке, а параграф «О разсужденіи лихвы» представляет собой тематически исчерпывающее, логически стройное и аргументированное рассмотрение проблемы ростовщичества, вполне допустимо предположить, что для данного сюжета 
компиляторы Мира с Богом использовали какой-то готовый текст. На эту мысль наводит и отчасти диалогический характер повествования, совершенно не свойственный всем другим разделам православного памятника.

Известно, что католическое богословие XVI-XVII вв. и особенно богословская школа в Саламанке активно разрабатывали экономические сюжеты, а значительное число рассуждений о ростовщичестве принадлежит перу иезуитов (HANSEN 1964, LIPIŃSKI 1975: 138). Ими был создан ряд самостоятельных, хотя и немногочисленных в ту эпоху трактатов. К числу наиболее исчерпывающих на эту тему в XVI в. сочинений относится Disputatio de usura испанца Диего Лайнеса (1512-1565), написанное около 1544 г., но опубликованное лишь в XIX веке (O’MALLEY 1999: 231). Гораздо чаще рассуждения о ростовщичестве встречались в составе разнообразных богословских компендиумов и «сумм» для исповедников, число которых исчислялось в ту эпоху сотнями.

В Речи Посполитой интерес к данной теме возникает лишь на рубеже XVI-XVII вв. и находит свое выражение в монографическом сочинении O lichwie $i$ trzech przedniejszych kontraktach связанного с Виленской Академией Общества Иисуса польского иезуита Марчина Смиглецкого (Marcin Śmiglecki, 1563/1564-1618). Опубликованное впервые в 1596 г., сочинение переиздавалось до середины XVII века 10 раз с некоторыми добавлениями, часть из которых была внесена самим Смиглецким (DAROWSKI 1993-1994: 213). С издания 1607 г. сочинение именовалось O lichwie $i$ wyderkach.

Трактат носит богословско-правовой характер, в нем анализируются различные ситуации дачи денежных средств или материальных ценностей в долг и взимания процентов с прибыли, полученной от использования этих сумм или ценностей. Несмотря на преимущественно экономическую на первый взгляд тематику сочинения, оно задумывалось в первую очередь как практическое пособие для духовников, которые во время исповеди принимали решение, является ли конкретный случай взимания процентов с прибыли грехом или нет (DRZYMAŁA 1981: 30-33). Уникальность трактата Смиглецкого состояла в том, что он носил монографический характер, что было еще большой редкостью в ту эпоху (DAROWSKI 1993-1994: 224).

В своем законченном виде сочинение состояло из четырех частей и 12 разделов; сюжету ростовщического процента отводились лишь первые четыре раздела книги, которые и были использованы составителями Мира с Богом. При том, что текст Смиглецкого переводился практически дословно, православные компиляторы опустили целый ряд весьма примечательных фрагментов. Так, были изъяты ссылки на конкретные богословские сочинения латинских авторов и заменены на безличные обороты типа «оучителя оуставиша», что было одной их самых распространенных техник работы православных книжников с иноконфессиональными памятниками (Корзо 2011: 41-49). Не попало в православный трактат замечание о том, что ростовщичество запрещено не только Божьим, церковным и светским правом, но и естественным законом (МБ 1669: 537). Были изъяты аргументы в пользу 
допустимости контролируемых государством публичных домов в городах и исторические экскурсы о том, что древним евреям разрешалось иметь наложниц не еврейского происхождения - эти сюжеты возникают у Смиглецкого как иллюстрации его рассуждений вокруг проблемы меньшего зла. Православные компиляторы проявили особую чувствительность к употреблению слова «еврей» и всех его производных, в отдельных случаях совершенно опуская эти слова, а в других подбирая для них не всегда удачные тавтологии: так, например, выражение Смиглецкого «żyd lichwi» (ŚMIGLECKI 1596: $29)$ переложили как «лихваръ лихвит» (МБ 1669: 547). Посредством трактата польского иезуита православные компиляторы позаимствовали целый ряд богословских терминов в их схоластической форме, совершенно чуждых предшествующей православной традиции.

Несмотря на хорошее владение православными книжниками той эпохи латинским языком, представляется совершенно очевидным, что именно наличие польских переводов Андроцци и выбор Смиглецким для своего трактата польского, а не латинского языка, стало решающим аргументом для православных в обращении к данным памятникам в качестве источников для своих - православных текстов. Правда, в сохранившихся описаниях православных библиотечных собраний Речи Посполитой интересующие нас сочинения Андроцци и Смиглецкого не встречаются. А потому о знакомстве православных книжников с этими (а также и со многими другими!) католическими авторами мы можем судить исключительно на основе кропотливой реконструкции, какие конкретно сочинения были переведены и «спрятаны» внутри православных текстов.

\section{Литература}

BACKer-Sommervogel 1890 = De BACKer d'Alois, Sommervogel Charles: Bibliothèque de la Compagnie de Jésus I. Bruxelles-Paris, 1890.

Boge-Bogner 1999 = Boge B., Bogner R. G. (Hg.) Oratio funebris. Die katholische Leichenpredigt der frühen Neuzeit. Amsterdam, 1999.

Brogi BerCoff 1992-1993 = Brogi Bercoff Giovanna: The Letopisec of Dimitrij Tuptalo, the Metropolitan of Rostov, in the Context of Western European Culture. Ricerche Slavistiche 39-40 (1992-1993): 293-364.

CHARIPOVA 2006 = CHARIPOVA Ludmila V. Latin Books and the Eastern Orthodox Clerical Elite in Kiev (1632-1780). Manchester-New York, 2006.

DAROWSKI 1993-1994 = DAROWSKI Roman: Marcina Śmigleckiego SJ traktat „O Lichwie" (1596). Rocznik Wydziału Filozoficznego Towarzystwa Jezusowego w Krakowie 5 (1993-1994): 209-228.

DrZYMAŁA 1981 = DrZYMAŁA Kazimierz: Ks. Marcin Śmiglecki TJ. Kraków, 1981.

Hansen 1964 = Hansen Klaus: Petrus Canisius's Stand on Usury. An Example of Jesuit Tactics in the German Counter Reformation. Archiv für Reformationsgeschichte 55 (1964): 192-203.

HEALEY 2011 = HEALEY Robin: Italian Literature before 1900 in English Translation. An Annotated Bibliography (1929-2008). Toronto, 2011. 
KAPUŚCIŃSKA 2016 = KAPUŚCIŃSKA Anna: Theatrum meditationis. Ignacjanizm i jezuityzm w duchowej i literackiej kulturze Pierwszej Rzeczypospolitej - źródła, inspiracje, idee. In: NowICKA-Jeżowa Alina (red.): Drogi duchowe Katolicyzmu polskiego XVII wieku. Warszawa, 2016. 119-229.

Korzo 2012 = Korzo Margarita A. Dzieła Mikołaja z Mościsk OP i teologów zachodnich źródłem pierwszego manuale dla spowiedników w języku cerkiewnosłowiańskim. Przeglad Tomistyczny 18 (2012): 241-253.

LIPIŃSKI 1975 = LIPIŃSKI Edward: Historia polskiej myśli społeczno-ekonomicznej do końca XVIII wieku. Wrocław-Warszawa, 1975.

NIEDŹWIEDŹ 2012 = NIEDŹWIEDŹ Jakub: Kultura literacka Wilna (1323-1655). Retoryczna organizacja miasta. Kraków, 2012.

O’Malley 1999 = O’Malley John W. Pierwsi jezuici. Kraków, 1999.

Possevino 1606 = Possevino Antonio: Apparatus Sacer ad scriptores veteris et novi Testamenti I. Venetiis, 1606.

SchotTROFF 2012 = SchOtтRoff Luise: Die Bereitung zum Sterben. Studien zu den frühen reformatorischen Sterbebüchern. Göttingen, 2012.

SCHRÖDER 2001 = SCHRÖDER Bianca-Jeanette: Materia. In: Historisches Wörterbuch der Rhetorik. Bd. 5. Tübingen, 2001. 990-996.

Scieszka 1600 = Scieszka poboznego chrześcianina to iest Nauki y przestrogi co potrzebnieysze na poratowanie wszytkich zbawienia pragnacych. Kraków, 1600.

Skarbnica duchowna 1600 = Skarbnica duchowna rozmaite ksiażeczki nabożne z drogimi naukami w sobie zamykajaca. Wilno, 1600.

SKWARA 1999 = SKWARA Marek: O dowodzeniu retorycznym $w$ polskich drukowanych oracjach pogrzebowych XVII wieku. Szczecin, 1999.

SKWARA 2009 = SKWARA Marek: Polskie drukowane oracje pogrzebowe XVII wieku. Bibliografia. Gdańsk, 2009.

ŚMIGLECKI 1596 = ŚMIGLECKI Marcin: O lichwie i trzech przednieyszych kontraktach: wyderkowym, czynszowym y towarzystwa kupieckiego nauka krótka. Wilno, 1596.

TOPOLSKA 1984 = TOPOLSKA Maria: Czytelnik i książka $w$ Wielkim Księstwie Litewskim $w$ dobie Renesansu i Baroku. Wrocław, 1984.

WINKLER 1967 = WINKLER Eberhard: Die Leichenpredigt im deutschen Luthertum bis Spener. München, 1967.

ІСАєВИЧ 2002 = ІСАєВИЧ Ярослав: Украӥнське книговидання: витоки, розвиток, проблеми. Львів, 2002.

КоРзо 2011 = КоРзо М. А. Нравственное богословие Симеона Полоикого: освоение католической традиции московскими книжниками второй половины XVII века. Москва, 2011.

МБ $1669=$ Мир с Богом человеку. Киев, 1669.

Требник 1621 = Требник сиречь Молитовникъ. Вильно, 1621.

ЧистяковА 2017 = ЧистяковА М. В. Рукописные Прологи Великого княжества Литовского и Польского королевства. Kraków, 2017.

ЧуБА 2011 = ЧуБА Галина: Украӥнські рукописні учительні Свангелія. Дослідження, каталог, описи. Київ-Львів, 2011.

ШустовА 2009 = ШустовА Ю. Э. Документы Львовского Успенского Ставропигийского братства (1586-1788). Источниковедческое исследование. Москва, 2009.

Яковенко 2017 = Яковенко Наталя: У пошуках Нового неба. Життя і тексти Йоаникія Галятовського. Київ, 2017.

ЯРеменКО 2007 = ЯРеменКО Максим: Київське чернецттво XVIII cm. Київ, 2007. 